\title{
Reading Comprehension and Reading Comprehension Difficulties
}

Oakhill, Jane V.; Cain, Kate; Elbro, Carsten

Published in:

Reading Development and Difficulties

DOI:

10.1007/978-3-030-26550-2_5

Publication date:

2019

Document version

Peer reviewed version

Document license:

Unspecified

Citation for published version (APA):

Oakhill, J. V., Cain, K., \& Elbro, C. (2019). Reading Comprehension and Reading Comprehension Difficulties. In D. A. Kilpatrick, R. M. Joshi, \& R. K. Wagner (Eds.), Reading Development and Difficulties: Bridging the Gap Between Research and Practice (pp. 83-115). Springer. https://doi.org/10.1007/978-3-030-26550-2_5 
[Oakhill, J., Cain, K., \& Elbro, C. (2019). Reading Comprehension and Reading Comprehension Difficulties. In D. A. Kilpatrick, R. M. Joshi \& R. K. Wagner (Eds.), Reading Development and Difficulties: Bridging the Gap Between Research and Practice (pp. 83-115). Cham, Switzerland: Springer International Publishing.]

\section{Reading Comprehension and Reading Comprehension Difficulties}

Jane Oakhill, Kate Cain, \& Carsten Elbro

\section{Introduction}

Reading comprehension is crucial not just for understanding text, but for learning more generally and, thus, education more broadly. It is also requisite for social activities because of email, texting and the numerous web applications that people use on an everyday basis. In this chapter, we will explore how successful reading comprehension requires the orchestration of a number of different abilities and processes for its success.

\section{The Simple View of Reading}

In this chapter, we focus on the language skills that underpin successful reading comprehension. It goes without saying that readers will not be able to understand a text if they cannot decode a reasonable number of the words in it. But effective reading comprehension also requires good language understanding more generally. Critically, reading comprehension cannot take place in the absence of either one of these components: if a child cannot read any words and/or if a child has no language comprehension ability, their reading comprehension will be zero. This is the essence of the Simple View of Reading (originally proposed by Gough \& Tunmer, 1986). The Simple View of Reading does not imply that reading, or learning to read, is "simple" but, rather, that variation in reading ability can be captured (simply) by variation in these two skills. It is a useful framework for understanding not only reading development, but also reading difficulties.

The development of reading. For the beginning reader, word reading is new, and children will differ substantially in how quickly they acquire the ability to decode the words on the page. Language comprehension, on the other hand, is quite well developed when children start school. So, in beginning readers the 
variation in reading comprehension is almost identical to the variation in word reading. As children become competent at decoding the words, good language comprehension will be more crucial to their overall reading comprehension than word recognition.

This change in the influence of word reading and language skills in the first few years of reading development does not mean that early reading instruction should focus solely on teaching children how to decode words. Even though children typically have a high level of communicative competence by the time they begin to learn to read, written texts are, in important ways, different from spoken interactions and typically require memory abilities and other cognitive skills that are not so crucial in understanding everyday face to face spoken interactions, that typically happen in the 'here and now.' We review the critical skills for reading comprehension under different categories below.

Reading difficulties. The Simple View of reading is often presented schematically, as in Figure 1, to illustrate the sources of variability among students in their reading skills. This schematic representation shows how problems with one component of reading can occur independently of problems with the other. For example, children with specific comprehension problems can be differentiated from children who have specific word reading problems (i.e. dyslexics) or generally poor readers (sometimes termed "garden variety" poor readers).

\begin{tabular}{|lll|}
\hline & Language comprehension \\
\hline Word reading & Poor & Good \\
\hline Poor & Generally poor reader & Dyslexic \\
\hline Good & Poor comprehender & Good reader \\
\hline
\end{tabular}

Figure 1. The Simple View of Reading.

Children with specific comprehension problems (often simply termed 'poor comprehenders') have difficulties with reading comprehension, despite having age-appropriate word reading skills. The problems of such children often do not become apparent before the $3^{\text {rd }}$ or $4^{\text {th }}$ year of schooling, because such children are perceived as 'good readers' (i.e. good at word decoding) and the material they are being asked to read and understand in the early years of school is typically not very demanding in terms of language comprehension (which encompasses a number of skills we will outline below). Thus, as the texts they are expected to read and understand become increasingly complex, some children who initially seemed quite competent at reading might turn out to have 
reading comprehension problems (e.g., Catts, Compton, Tomblin \& Bridges, 2012). These children with specific reading comprehension problems, i.e., the poor comprehenders, will be the focus of this chapter.

\section{What Does it Mean to Comprehend a Text?}

Whatever the modality in which a text is presented (i.e. whether written down or read aloud), successful comprehension involves the construction of an integrated representation of the overall meaning of the text. This example (taken from a study of reading comprehension) will give you an idea of the importance of building this representation.

"The man was worried. His car came to a halt and he was all alone. It was extremely dark and cold. The man took off his overcoat, rolled down the window, and got out of the car as quickly as possible. Then he used all his strength to move as fast as he could. He was relieved when he finally saw the lights of the city, even though they were far away" (from Bransford \& Nitsch, 1978).

If you are like most readers, you may say that there is nothing exactly wrong with the text. However, you may find it hard to understand and hard to recall. The problem is that it is difficult to set up a suitable mental model from the start of the text. What is the setting? Why is the man worried? On closer inspection, some things do not fit with the text: Why does the man take off his coat and roll down the window when it is extremely cold?

A suitable mental model could be 'man escapes from car driven into water'. With that model in mind, each piece of information from the text makes sense, i.e., can be integrated. The text will also be much easier to remember at a later point. That is because you remember your mental model of the text, not the text itself. This integrated representation of the meaning of a text has been termed a mental model (Johnson-Laird, 1983) or a situation model (Kintsch, 1998).

In the remainder of this chapter, we consider the skills and processes that are needed in order to understand a text. The comprehension processes we outline are central not only to reading comprehension but also to listening comprehension, with an important caveat: listening comprehension is intended as the understanding of a text read out loud, and not listening in the sense of everyday conversations and interactions.

\section{Vocabulary and Word Meanings}

It is possible for a competent decoder to read out loud all the words in a text, but to understand very little of the actual text, as in this example 
"The first model that was able to explain the full spectrum of thermal radiation was put forward by Max Planck in 1900. He proposed a mathematical model in which the thermal radiation was in equilibrium with a set of harmonic oscillators. To reproduce the experimental results, he had to assume that each oscillator emitted an integer number of units of energy at its single characteristic frequency, rather than being able to emit any arbitrary amount of energy. In other words, the energy emitted by an oscillator was quantized. The quantum of energy for each oscillator, according to Planck, was proportional to the frequency of the oscillator; the constant of proportionality is now known as the Planck constant." (from "Introduction to Quantum mechanics", Wikipedia)

Good reading comprehension depends on knowledge of the meanings of the words in the text. The strong relations between vocabulary knowledge and reading comprehension have been acknowledged for many years (e.g. Carroll, 1993; Davis, 1944, 1968; Thorndike, 1973). Some estimate that about $90 \%$ of the words need to be known for a reader to have a good chance of understanding a text (Nagy \& Scott, 2000).

However, good reading comprehension is also an invaluable source of word knowledge. For a start, it is not necessary to know all the words in a text, or to stop to look up all unknown words because, to some extent, the meanings of unknown words can be worked out from the context. New items are added to our vocabularies throughout our lifetimes and, similarly, existing vocabulary is refined through reading. Once children become fluent readers, written text will be a major source of new vocabulary items (Cunningham, 2005; Nagy \& Scott, 2000).

The relation is reciprocal: vocabulary development and reading comprehension can have a beneficial effect on each other (e.g., Seigneuric \& Ehrlich, 2005). This relation of mutual reciprocity between vocabulary and comprehension means that readers can enter either virtuous or vicious circles. With limited vocabulary knowledge, comprehension is likely to suffer, and without a basic level of comprehension, the ensuing vocabulary learning is likely to be minimal. Conversely, a skilled reader with relevant prior knowledge and good vocabulary can learn a lot from the same text. These positive or negative circles are frequently referred to as the Matthew Effect in reading (Stanovich, 1986). 


\section{Different Aspects of Vocabulary and their Relation to Reading}

\section{Comprehension}

It is not easy to say what it means to know a word. It is difficult because 'knowing' a word spans all the way from superficial recognition - "I think I have heard the word pelagic before, but I am not sure I know what it means" - to being able to explain the word's meaning in depth and providing appropriate examples of usage.

In other words, vocabulary knowledge is not all or none, there are different degrees of knowledge of the meaning(s) of a word. Measures of vocabulary knowledge at shallow levels are also known as measures of vocabulary breadth. Such measures typically require simple recognition or production of single words as in the British Picture Vocabulary Scale, (BPVS: Dunn, Dunn, Whetton, \& Pintillie, 1992).

The amount and detail of knowledge of words is often referred to as depth of vocabulary knowledge, and this can include not only definitional knowledge of a word, but also the relations and associations between individual words and concepts. For example, knowledge about pulmonary barotrauma might include the information that it is something SCUBA divers might be prone to. More "in depth" knowledge might include the fact that it typically occurs if a diver holds his/her breath while ascending, and that it is a serious and potentially fatal condition. Even deeper knowledge would include the information that a pulmonary barotrauma occurs when the pressure inside the lungs becomes too great so that the lung is ruptured. Incidentally, in this instance morphological decomposition can also help with working out (and remembering) the meaning of the expression. You would need to know that pulmonary relates to lungs (as in pulmonary disease, pulmonary embolism, etc.), and consideration of the composition of barotrauma makes it obvious that it has two morphemes: baro, meaning pressure (as in bar, barometer) and trauma, meaning some sort of damage. So a morphological analysis of pulmonary barotrauma may lead to the meaning 'pressure damage to the lung', or more colloquially 'burst lung'.

There is now increasing evidence that comprehension is particularly dependent on vocabulary knowledge at relatively deep levels (Ouellette, 2006; Tannenbaum, Torgesen, \& Wagner, 2006). There are many reasons why readers need a relatively deep understanding of words: First, when concepts that have names occur in a text, such as barotrauma or table, it will be easier for the reader to understand the text the more s/he knows about those words. If the reader can activate an appropriate, more detailed and contextually relevant, instance at the first encounter of the key word (e.g., Anderson, Stevens, Shifrin, \& Osborn, 1978) that is likely to facilitate subsequent comprehension. For instance, if a reader sees the text "The fish attacked the surfer", the instantiated representation of the fish in question is some sort of large and aggressive fish, most likely a shark, not 
just any old generic fish. A related issue is that a reader might have quite a detailed meaning representation of a word, but might fail to activate and use that knowledge to make appropriate inferences during comprehension (Cain \& Oakhill, 1999; Cain, Oakhill, Barnes \& Bryant, 2001).

Reading comprehension occurs in real time, so it is crucial that the reader is able to access word meanings (and, indeed, other sorts of knowledge), rapidly and accurately. If the activation of meanings is too slow, it will be difficult to process the links with other words in the text before the next word is encountered. Thus speed of activation should be added to the requirements for having a rich vocabulary. It is not enough to know lots of word meanings if it takes a long time to activate them. In our own recent research, for example (see Oakhill, Cain, \& McCarthy, 2015; Oakhill, Cain, McCarthy \& Field, 2012) we explored different aspects of children's vocabulary knowledge and the relation between those different aspects of knowledge and comprehension skill. We assessed not only children's knowledge of words at deeper levels, but also assessed their facility of access to the word meanings. The children in the study were asked to produce synonyms or hypernyms, e.g. "an apple a sort of what?" (answer: fruit), and were also asked to do speeded synonym and hypernym judgments on word pairs. So, for example, they had to judge as quickly as possible whether the first item was a "type of" the second, e.g. bread-food, foxvegetable. The results showed that children's vocabulary knowledge at deep levels, and in particular the speed with which that knowledge could be accessed, was predictive of their comprehension skill even when word reading ability and general speed of responding were taken into account.

\section{Vocabulary Development}

Even in very young children, vocabulary learning is already dependent on inference making (see the next section), because very young children cannot be taught word definitions. Instead, they typically have things labelled for them, and have to extract and refine meanings themselves by working out what the crucial features are. Indeed, they might focus on salient, but not necessarily definitional features. For example, a child might learn the word $d o g$ and apply it appropriately to refer to dogs, or pictures of dogs, but might also overextend the meaning to cats, pigs, cows, horses and, indeed, all four-legged animals.

The reciprocity between vocabulary development and reading comprehension is apparent in young children (pre-readers). Lepola, Lynch, Laakkonen, Silven, \& Niemi, (2012), assessed children's ability to make inferences about stories in picture books, and they found that this skill when the children were age 4 predicted their vocabulary knowledge one year later, which subsequently predicted their listening comprehension at 6 . This finding indicates that it is important to foster and develop children's inference skills even before 
they can read. Not only are inference skills important for text comprehension (as we outline later in the chapter), but they are also important in developing vocabulary knowledge.

Once children start reading, most new vocabulary is learned through reading, not from being directly taught word meanings (Cunningham, 2005). Hence the quality and the amount of reading is important for the further development of vocabulary - and thereby for reading comprehension. The mediating variable seems to be amount of reading experience. Children who have good comprehension (or good vocabulary, or both) are likely to read more (and enjoy reading more), and thus improve their vocabulary (and comprehension) through practice in reading.

There are very substantial differences in the amount of reading that children do voluntarily. It has been estimated that during the middle grades an average reader might read 100,000 words a year, while a more highly motivated child might read 1,000,000 words. Really voracious readers might read 10 million or even up to 50,000,000 words in a year (Nagy \& Anderson, 1984). These very substantial individual differences between readers will lead to similarly substantial differences in vocabulary and comprehension in later years.

The relation between vocabulary knowledge and reading comprehension changes developmentally. Vocabulary becomes more important as a predictor of comprehension skill between about 7 and 10 years (Protopapas, Siderisis, Mouzaki, \& Simos, 2007). This change probably occurs because, as children become more skilled and fluent word decoders, vocabulary knowledge becomes more crucial and also because as children get older, the books that they need to read become more challenging in terms of vocabulary (reading books for beginners are typically written with a restricted word set).

\section{Vocabulary and Reading Comprehension}

There are different ways in which vocabulary knowledge and reading comprehension may be related:

First, poor comprehension restricts vocabulary growth: children with specific reading comprehension difficulties have slower rates of vocabulary growth than same-age peers with good reading comprehension (Cain \& Oakhill, 2011).

Second, there is not a clear causal link between vocabulary breadth (see above) and comprehension. Children identified as poor comprehenders typically perform within the normal range on measures of receptive vocabulary, but such children may have problems with other aspects of vocabulary (Cain, Oakhill \& Lemmon, 2004). 
Third, some poor comprehenders also perform relatively poorly on measures of activation of word meanings and related words, for example on tests of vocabulary fluency. They generate fewer category instances than good comprehenders (for example: name as many kinds of farm animals as you can), but do not have similar problems when asked to generate words that rhyme with a given word (name as many words that rhyme with farm as you can). Thus, the problem is specific to tasks requiring access to word meanings (Nation \& Snowling, 1998).

In addition, there is evidence that poor comprehenders are less likely than good comprehenders to activate meaning-related words automatically. For instance, we used a false memory task to assess good and poor comprehenders' gist memory for word lists (Weekes, Hamilton, Oakhill \& Holliday, 2008). This task employs the DRM paradigm (Deese, 1959; Roediger \& McDermott, 1995) in which people are required to remember (recall or recognize) a list of words, such as: bed, rest, tired, dream, wake, snooze, blanket, doze, slumber, snore, nap, peace, blanket, yawn, drowsy. In such tasks, both adults and children very often recall or recognise words that were not in the list, but which capture the gist, or theme, of the list (i.e. sleep, in the above list). It was the good comprehenders who were more likely to misremember the theme words, although there were no differences in memory for the words that actually appeared in the lists.

\section{Teaching Vocabulary}

There is evidence that reading comprehension can be improved by substituting easier vocabulary words for harder words, and instruction in the meaning of more difficult words, can improve comprehension (Kameenui, Carnine \& Freschi, 1982). However, the adaptation of texts for children with poor vocabularies is clearly not a viable strategy in the longer term. First, logistically, this is not practicable and, second, it is important that children learn to infer meanings from context so that they increase their vocabulary and not just have texts simplified to the level of their existing vocabulary.

There have been a number of studies of different methods of teaching vocabulary to children, but none of these methods will dramatically expand and deepen their vocabulary. The immediate results of vocabulary training are moderate, and the transfer effects to reading comprehension are even less substantial, and have only been demonstrated in a small number of studies (NRP, 2000). However, there are promising ways in which the interplay between vocabulary knowledge and reading comprehension may be improved.

Two different approaches to teaching vocabulary can be distinguished. The most obvious is simply to help children learn the meanings of specific words. The other is to help children become better at figuring out meanings of new words 
through independent reading. Both methods can support reading comprehension. These methods are described in turn in the next section.

Teaching specific words. Authors of school texts often take word knowledge for granted even though many words may be unfamiliar to children. In such cases, it can be helpful to explain they key words and to link them to topic knowledge before the children read the text. When such words are known, it is much easier to use them to build mental models of the content of the text. For instance, for 5th-grade students, teaching relevant vocabulary has an effect on learning of, and memory, for a social studies text (Carney, Anderson, Blackburn, \& Blessings, 1984), and Medo and Ryder (1993) found that vocabulary instruction helped eighth grade students to make causal connections in an informational text, a method that was beneficial across a wide range of ability levels.

In addition to key words, other words may also be targeted for direct teaching. These are words that children are likely to encounter frequently in texts in a variety of content areas as they enter higher grade levels, words such as coincidence, absurd, hasty, perseverance ("tier two words"1 in the US, Beck, McKeown \& Kucan, 2005). They are neither the most frequent and earlyacquired words ("tier one" words, such as clock, baby, happy) nor infrequent, topic-specific words ("tier three" words, such as osmosis, nucleus, archeologist). Since words are learned in approximately the same order no matter whether they are learned at the age of 7 or 10 , tier two words are the ones that are either just included or about to be included in the child's vocabulary (Biemiller, 2005). As such, they are among the most useful words to teach.

There are numerous ways to teach vocabulary but, based on the research thus far, some methods and strategies are likely to be more helpful than others. First, as would be expected given the links between vocabulary and reading comprehension, the successful teaching of vocabulary needs to be aimed at deeper levels of vocabulary knowledge. This means that children should not just learn word definitions, but also how unfamiliar words relate to other words. So, for example, it is not enough to learn that a 'shitzou' is a name of a particular animal. It is much more efficient to know that a shitzou is a type of dog, in which ways it is a typical dog, and how it differs from most other dogs. In this way, shitzou will be linked to many other words and concepts in a "semantic network" (or meaning network). In practice, this means that vocabulary teaching should take place in a rich context (Beck, Perfetti \& McKeown,1982; NRP, 2000), and the

\footnotetext{
${ }^{1}$ It should be noted that the usage of the term "tier" by Beck et al. (to denote three levels of vocabulary) is different from the use of that term in the context of Response to Intervention (RTI).
} 
formation of connections (networks) between words should be actively encouraged. Second, vocabulary learning is also enhanced when children are given opportunities to detect and to use new words, e.g. during dialogues with the teacher (Coyne, McCoach \& Kapp, 2007). The teacher can support learning by asking increasingly demanding questions about new words (e.g., Blewitt, Rump, Shealy, \& Cook, 2009). Third, repetitions of new vocabulary items are also supportive of learning, as pointed out in the survey of training studies by Stahl and Fairbanks (1986). So, for example, pre-reading activities with key words should be followed up by activities on what has been learned about these words during reading, and follow-up activities on later occasions. For younger children, simple re-reading of storybooks will provide them with important opportunities to rehearse the meaning of new words (Biemiller and Boote, 2006).

Teaching children to acquire new vocabulary. Even though it may be possible for children to learn 10 new words a week through a well-structured vocabulary training programme (Biemiller, 2005), such a programme would help children to acquire only about 400 new words a year. This would still only be a small fraction of the words that children typically acquire in a year. A further complication is that it would be difficult for the teacher to predict which key content words the children would need to know in the longer run. Thus, some more recent programs (see below) teach children word knowledge and inference making abilities that can help them acquire new word knowledge during independent reading.

There are two main ways in which children can be helped to improve their incidental learning of new vocabulary. These are not mutually exclusive; rather, they may supplement each other. One way is to instruct children in ways to derive meanings from context. Children can be taught to search the context for clues about the category of the unknown word ("what sort of thing is it?"), for defining characteristics ("how can you describe it?") and for likes and opposites ("do you know of something similar or the opposite?"). For instance, Tomesen and Aarnoutse (1998) found that such direct instruction was helpful in improving the text comprehension of both poor and average readers. However, the skills did not transfer to the children's reading comprehension more generally.

Another way is to teach word knowledge through morphology, that is, through knowledge of the smallest significant units of words: prefixes, roots, suffixes, inflections, e.g. mis/read/ing/s (see Bowers \& Kirby, 2010). The same root morphemes occur in several different words, e.g. the root read is part of reads, reader, unread, reading etc., and derivations and inflections apply to whole classes of words. So, learning a morpheme in one word is potentially beneficial for recognising and understanding many new words in which the morpheme 
occurs. For example, if you know that the morpheme eval relates to 'age' then you will see that medieval means "middle age", primeval means "first age" and you can probably work out the meaning of "coeval" if you don't already know it. Numerous studies have found that teaching morphology to children has significant effects on the development of both vocabulary and reading comprehension. Such effects are enhanced if teaching does not just focus on the analysis of single words but is combined with comprehension instruction (see Bowers, Kirby \& Deacon, 2010)

Successful training programs typically explicitly emphasise the interrelations between the orthographic, phonological, morphological, semantic and syntactic aspects of reading (so called "lexical quality" of the word: Perfetti, 2007). The idea behind such training is that the more one knows about a word (i.e., its phonemes, orthographic patterns, semantic meanings, syntactic uses, and morphological roots and affixes), the more efficiently the word can be decoded, retrieved, and comprehended. Such a program, called RAVE-0 (Barzillai, Morris, Lovett \& Wolf, 2010), which focuses on training meaning in the context of the other linguistic properties of the word to be learnt, has been shown to improve second and third grade poor readers' vocabulary knowledge. This training was effective not only for the multiple meanings of the words taught within the program, but also improved the children's knowledge of the meanings of words not taught within the program. Importantly, these gains were maintained one year later.

\section{Inferences}

Most texts are far from explicit and, indeed, they would be very long and tedious if they were. Inferences are licensed by the text, but they go beyond the information that is stated explicitly. Good stories, and novels in particular, create opportunities for the reader to make inferences to work out what is going on. Consider the following three sentences:

Mary heard the ice-cream van coming.

She remembered her pocket money.

She rushed into the house to get it.

You almost certainly spontaneously made links between those sentences so that they were no longer independent. She in the second and third sentences refers back to Mary in the first sentence and, thus, provides a link between those sentences. Similarly, it in the final sentence refers back to Mary's pocket money. The inferences that you made to link these sentences are local cohesion inferences (often called bridging inferences). The need to generate a local 
cohesion inference is often signalled by pronouns, and other explicit cues in the text. Another critical type of inference is a global coherence inference. The reasons for Mary's thoughts and actions are not stated in the text but, like most readers, you most probably made a global coherence inference to understand that Mary has the intention to buy an ice cream, using her pocket money. In doing so, you drew on your background knowledge about such events. Global coherence inferences such as these contribute to the meaning and coherence of the text overall.

This example shows that even a very short, apparently simple, text requires numerous inferences. What is important to note is that the examples above are of inferences that are necessary to understand the essence of the text. For example, a reader might infer that Mary cannot find her pocket money in time, and does not succeed in her goal of buying an ice cream, or that Mary's favourite ice cream is strawberry, but those inferences are not necessary to construct a coherent representation of the three sentences. Such inferences can be considered as elaborative in that they embellish the mental model. Although they might be helpful in some circumstances, they could actually be detrimental to understanding because they are not licensed by the text, and might turn out to be not just irrelevant, but wrong (as well as being time-consuming and distracting). It is connecting inferences, which help to establish local and global coherence in text, that need to be encouraged and facilitated in young readers.

\section{The Development of Inference Making}

Inference making is important for understanding the world, not just for text comprehension, thus it is not surprising that children have the ability to make the types of inferences necessary to understand text from an early age, before formal reading instruction begins. Preschool children are able to generate inferences from picture books, stories read aloud to them, and animated cartoon sequences (Kendeou et al., 2005; Language and Reading Research Consortium, 2015; Silva \& Cain, 2015). However, inference making ability continues to improve between the ages 6 to 15 years, with not even the oldest children achieving 100\% accuracy (Barnes, Dennis, \& Haefele-Kalvaitis, 1996). So what are the key factors that support developmental improvements?

First, it is clear that younger children's memory limitations might restrict their ability to make inferences. Memory capacity develops across a wide age range (Gathercole, Pickering, Ambridge, \& Wearing, 2004). Children need to remember accurately key parts of the text to construct a mental model. One aspect of memory that is particularly important for inference making is working memory: the ability to process information whilst storing previously read or heard information used when the reader (or listener) needs to link information 
between different sentences in a text and/or incorporate background knowledge to make sense of implicit details. Memory capacity is associated with children's ability to generate inferences between 6 and 12 years (Cain, Oakhill, \& Bryant, 2004; Chrysochoou, Bablekou, \& Tsigilis, 2011; Currie \& Cain, 2015). If a child has difficulty with inferential questions, it may be helpful to check that they remember the crucial pieces of information on which the inferences depend and also to check their working memory capacity.

A second factor that likely influences developmental differences in inference making is knowledge: both vocabulary knowledge and background knowledge related to the topic of the text. In order make the inferences outlined above, for example, the reader has to know the meanings of key words and also that we need money to purchase ice cream, etc. Depth of vocabulary knowledge (what we know about a word's meaning) is more strongly related to inference skill than breadth of vocabulary knowledge (how many words are known) (Cain \& Oakhill, 2014). Thus, building up rich, interconnected, semantic networks as vocabulary knowledge expands may, in part, explain developmental improvements.

The contribution that background knowledge makes to inference skills developmentally has been explored in beginner readers through to mid adolescence (Barnes et al., 1996). Of course, lack of relevant knowledge can limit inference making, but even when they have the relevant knowledge, some children do not access it and apply it to their understanding of text. It appears that not only depth of knowledge, but also facility of access to that knowledge, may be a critical determinant of children's inference making (see also Oakhill, et al., 2012).

A third factor to consider is a reader's (or listener's) standard for coherence and their active attempts to make the text cohere (van den Broek, 1997). This standard for coherence can vary both inter-individually (i.e., between readers) and intra-individually (i.e., within readers, e.g., depending on the purpose of reading). For instance, when adults are required to read to study for a test they generate more inferences than when required to read for entertainment (van den Broek, Lorch, Linderholm, \& Gustafson, 2001). Thus, it seems that readers set goals, and when it is important to make all of the critical links between information in a text and to derive conclusions from that text, they are able to do so. In contrast, when reading for pleasure, they might make a less deliberate effort because they regard the purpose as being entertained rather than to learn from the text. However, some children might not set appropriate standards for coherence and/or might not be able to make task-relevant adjustments to those standards. 


\section{Difficulties with Inference Making}

Children with reading comprehension problems do not generate as many necessary local cohesion and global coherence inferences as their peers (Cain \& Oakhill, 1999; Cain, et al., 2001; Oakhill, 1984). As was the case with developmental differences, three main factors seem to be particularly important: memory, knowledge, and a reader's standard for coherence.

Children with poor comprehension skills tend to have lower working memory capacity than children with good comprehension (Cain, 2006; Nation, Adams, Bowyer-Crane, \& Snowling, 1999; Oakhill, Yuill, \& Parkin, 1986), and independent measures of working memory predict inference making skill in typically developing readers (Cain, Oakhill, \& Bryant, 2004). For children with poor comprehension skills, memory is particularly predictive of their performance when the inference required the integration of information in sentences separated by several additional sentences (Barnes, Faulkner, Wilkinson, \& Dennis, 2004; Cain, Oakhill, \& Lemmon, 2004).

Vocabulary and background knowledge are important for inference making, as shown in our earlier example about Mary and the ice-cream van. Even very simple inferences cannot be made if the reader does not have the requisite background knowledge. However, when knowledge is carefully controlled for, poor comprehenders still make fewer inferences than good comprehenders (Cain et al., 2001). So, as was the case with younger readers, inferencing failures do not occur simply because poor comprehenders lack relevant knowledge. It may be that it is the activation of knowledge, and the speed with which that knowledge can be activated, rather than having knowledge per se, that are critical limiting factors.

Children's standard for coherence may also explain inference making difficulties between good and poor comprehenders. Children who are good comprehenders are sensitive to different task goals. For instance, when told that they will be tested on their memory for the content of a text, they take longer to read it and also remember more of its content compared to a 'reading for pleasure' goal. However, poor comprehenders do not adjust their reading in response to different goals (Cain, 1999).

\section{How Can Inference Making Ability Be Improved?}

It seems that there are, at least, three reasons why inference making might be hard for younger readers and poor comprehenders: poor memory, access to knowledge, and how able a reader is to set appropriate standards of coherence. Interventions to improve working memory have met with limited success, and transfer to reading comprehension has not been demonstrated (Melby-Lervåg \& Hulme, 2013). Here we briefly summarise the essence of two approaches to 
intervention that seek to raise awareness of when inferences are needed and also to show readers how to generate inferences from vocabulary and background knowledge. Thus, although not directly, these techniques both speak to access to knowledge and setting appropriate standards of coherence.

To raise awareness of the need to make an inference, children can be taught to quite literally question the text. In a recent classroom intervention, three questioning techniques were compared: Wh-questions, which in this study were: who, what, when, and where; causal inference questions; and also a general questioning technique in which students were asked "How does the sentence you just read connect with something that happened before in the story?" Each method resulted in gains in understanding, suggesting that a range of questioning protocols can be used to get students thinking about text and generating inferences (McMaster et al., 2012). One successful technique for teaching children how to make inferences from information in the text is to show them how to analyse the text for clues. Consider the sentence: 'Sleepy Jack was late for school again'. Sleepy suggests that the character may have overslept, thus providing a reason for being late for school, Jack combined with school suggests that this is a schoolchild and not a teacher who would most probably be introduced as $\mathrm{Mr} \mathrm{X}$, and again indicates that Jack is habitually late. Such interventions, combined with question generation, have resulted in gains in standardized assessments of reading comprehension (Yuill \& Oakhill, 1988).

A different approach uses graphic organisers to make students aware of their own contributions to inferences, by drawing on their background knowledge. Here is an example:

"During the 20th century, fishing boats became hugely more efficient so that it was possible to catch large quantities of fish in a short time. Towards the end of the century it became necessary to regulate fishing, for example by setting limits (quotas) on the catches of each fisherman or boat." (from Elbro \& BuchIversen, 2013).

An obvious question is why it has become necessary to regulate fishing. The answer requires a (causal) inference that draws on information both from the text and the reader's background knowledge, as illustrated in Figure 4.2. 


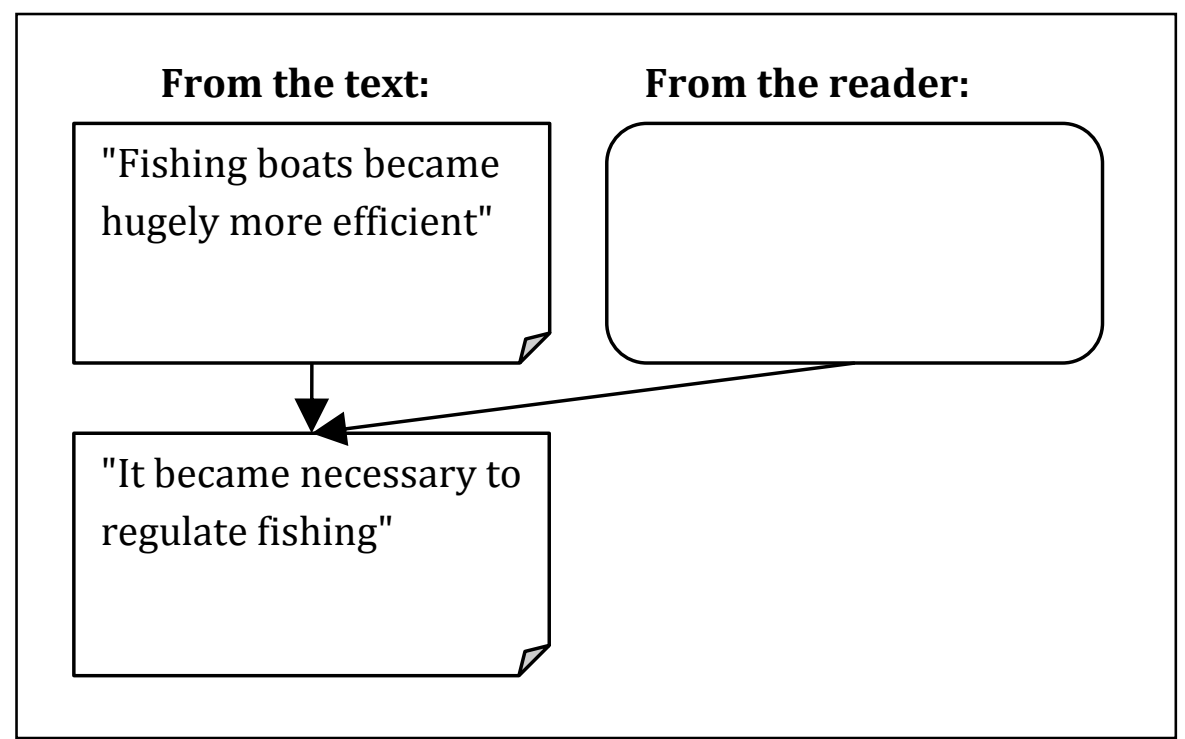

Figure 4.2. A graphic organiser can elucidate the contributions from both the text - and the reader, e.g., 'there is a limited amount of fish to be caught'.

In one study, 10- to 11-year-old students worked primarily with non-fiction texts and this technique had a strong and significant positive impact on the students' inference making during reading in general - and even a long term positive effect on their general reading comprehension (Elbro \& Buch-Iversen, 2013).

Thus, ways to improve inference making involve training children in different techniques that make them aware of the need to generate an inference, and also how to make those inferences by analysing the text and drawing on their background knowledge.

What about knowledge and vocabulary in inference making? Knowing the meanings of words is obviously crucial for reading comprehension and, as we have discussed above, for inference making in particular. So should inference training also focus on expanding vocabulary knowledge? As we noted above, speed of access to critical vocabulary and background knowledge appears to be more critical to inference making than knowledge per se, so training might usefully seek to focus on how to enable fast and accurate access to relevant information. One way to support fast access to vocabulary might be to foster rich and well-connected semantic networks. Our own work has shown that depth of vocabulary knowledge (what one knows about a word's meaning) is a stronger predictor of inference making than just breadth of vocabulary (how many words you know) (Cain \& Oakhill, 2014). There is also evidence that good comprehenders are more likely than poor comprehenders to activate meaningrelated words automatically (Weekes, et al., 2008). Thus, vocabulary instruction that emphasises the links between related words might help in this respect. 


\section{Monitoring for Meaning}

Comprehension monitoring is the process by which a reader (or listener) reflects on his or her own understanding. To be effective comprehenders, readers must not only be able to assess their understanding of what they have read, but also be able to apply appropriate strategies if they detect a comprehension failure. Such failures might arise for a number of different reasons. For example, a reader might simply have a lapse of attention and continue to "read" the text, without really taking it in. Or, they may lack relevant knowledge: they might not know the meanings of critical words or they may lack the relevant background knowledge that enables them to make sense of the text more generally. If readers are able to monitor their understanding, then they will have the opportunity to fix lapses in understanding providing they have the strategic abilities to do so. Thus, being aware of one's one understanding is important to ensuring adequate comprehension. However, younger children, and those with language and reading difficulties, may find it difficult to engage in comprehension monitoring because it depends on cognitive resources such as memory and attention.

\section{The Development of Comprehension Monitoring}

Children have the ability to monitor information for sense even before they begin to receive instruction in reading. Comprehension monitoring is often assessed by asking children to detect errors and inconsistencies in texts. For example, if a character is altered, or there is a change in the order of events in a familiar storybook, 3- to 4-year-old children will show surprise, an indication that they are monitoring their understanding (Skarakis-Doyle, 2002). However, children do not engage spontaneously in comprehension monitoring a lot of the time. Some classic examples of children's difficulties with comprehension monitoring come from studies by Ellen Markman. For example, Markman (1979) used texts with inconsistencies, such as those shown below.

\section{Explicit Condition}

One of the things children like to eat everywhere in the world is ice cream. Some ice cream stores sell many different flavours of ice cream, but the most popular flavours are chocolate and vanilla. Lots of different kinds of desserts can be made with ice cream. Some fancy restaurants serve a special dessert made out of ice cream called Baked Alaska. To make it they put the ice cream in a very hot oven. The ice cream in Baked Alaska melts when it gets that hot. Then they take the ice cream out of the oven and serve it right away. When they make Baked

Alaska, the ice cream stays firm and it does not melt.

(The inconsistent information is underlined). 


\section{Implicit Condition}

as above until ... To make it they bake the ice cream. As soon as it is finished baking they cut it into pieces with a knife and serve it right away.

Markman found that, in a sample of 8- to 11-year-olds, the majority of children failed to spot even quite blatant (explicit) inconsistencies, and even when asked explicit questions, such as: "Did I forget to tell you anything?" and "Did everything make sense?" they still did not pick out problems with the text about $50 \%$ of the time.

Markman's studies highlighted the difficulties that children have with comprehension monitoring tasks. There are a number of reasons as to why children might fail to spot even quite obvious problems, such as those in the example text above. First, they might be reluctant to criticize printed texts that are given to them by adults. Indeed, when children are explicitly informed that some texts contain errors, which gives them a license to be critical, their rates of detection improve. Second, children may be using different standards for monitoring to the one targeted by the experimenter. For instance, in Markman's (1979) study, the children's comments often indicated that they were engaging in monitoring behavior, but not in the way intended by the experimenter. For example, several of the children stated that they were checking that they knew the meaning of the words.

A subsequent study by Baker (1984) included texts with three different types of error: nonwords (as a proxy for unfamiliar vocabulary items), information that was inconsistent with general knowledge (external to the text) and information that was inconsistent with information presented elsewhere in the text (internal inconsistencies, similar to those used by Markman). In Baker's study, the children (aged 5 to 11) were told in advance that some of the texts contained errors, but those up to 7 years of age found the internal inconsistencies particularly difficult to detect.

Thus, there is evidence that children can monitor their understanding and, thus, spot errors and inconsistencies in texts, but they also indicate that it is important to develop sensitive methods to assess monitoring so that young children's abilities in this domain are not underestimated. Some further reasons as to why children might fail to adequately monitor their own comprehension are discussed in the next section.

\section{Difficulties with Comprehension Monitoring}

Not only young children, but also those with reading difficulties, and specifically those with specific reading comprehension problems, often fail to monitor their comprehension adequately. For example, a study by Oakhill, Hartt and Samols 
(2005) showed that children identified as poor comprehenders have difficulties in spotting internal inconsistencies in texts (of the sort described above), but have particularly marked problems when the inconsistencies are not in adjacent sentences in the text (i.e. the information that had to be integrated in order for the inconsistency to become apparent was separated by several sentences in the texts). Thus, memory limitations might, at least in part, explain why younger children and poorer comprehenders have difficulties with comprehension monitoring. A related possibility is that the poor comprehenders do not set up an adequate text representation (or mental model) as they read, so that information later in the text is not necessarily recognized as being in conflict with information presented earlier because the representation of the earlier text was inadequate or incomplete.

In sum, the research into children's comprehension monitoring shows that children are able to evaluate their comprehension from an early age, but the particular task they are set, as well as memory and attentional demands, are likely to influence how well they perform on monitoring tasks. Children with specific comprehension difficulties in particular show problems with comprehension monitoring, and there is evidence that comprehension monitoring skills are causally implicated in the development of good reading comprehension (Oakhill \& Cain, 2012).

\section{Teaching Comprehension Monitoring}

Good comprehenders can be characterized as active readers, who engage with a text during reading, and evaluate their own comprehension both during and after reading. Thus, it would seem that activities that encourage children to engage with the construction of meaning during reading are likely to improve

their comprehension monitoring. One way of training children to better monitor their comprehension is to present them with a specific task, such as pretending to be a detective. De Sousa and Oakhill (1996) found that children with comprehension problems were much better at detecting several types of text inconsistency (nonsense words, internal inconsistencies, and conflicts with prior knowledge) when they were told to pretend to be a detective and to read statements from witnesses to a crime, compared to when they were simply reading passages with the aim of spotting errors. Interestingly, the children in the comparison group of good comprehenders were not influenced by the instructions, presumably because they were already good at comprehension monitoring, and had little scope to improve their skills.

As mentioned above, merely alerting children to the fact that a text contains errors is often enough to improve their monitoring performance. This technique could be useful in modeling comprehension monitoring behaviour, to 
demonstrate to children the types of comprehension problems they might encounter in naturalistic texts, such as unfamiliar words, inconsistencies within the text, and conflicts with prior knowledge.

Another, more general, strategy that could be used to enhance comprehension monitoring could be to encourage children to stop and produce a summary at set points during reading or listening activities. It is not possible to produce a good summary unless you have understood the main points and ideas in a text, and the act of trying to produce a summary can be used as a tool to identify whether or not comprehension is progressing adequately, and there is evidence that comprehension monitoring is related to summarization skills. Indeed, self-directed summarization was one of the techniques included by Palincsar and Brown (1984) in a package of skills designed to help children to foster and monitor their own comprehension. The poor readers who were taught in that way produced better summaries than a control group and also performed better on a transfer test of comprehension monitoring.

A rather different technique - encouraging children to visualize a story as a sequence of mental images - has also been shown to improve comprehension monitoring. This technique is relatively easy to teach to children older than about 9 (Pressley, 1976), and supports memory for stories not only in poor comprehenders but also in typically developing readers. It has been shown that poor readers who were taught to use mental imagery improved their detection of inconsistencies in a comprehension monitoring task (Gambrell \& Bales, 1986), perhaps because the requirement to construct images helped the children to remember, and to compare, details from the stories. Although, at first gloss, use of imagery may seem very different from summarization techniques, to be successful both require the comparison and integration of information from different parts of a text.

\section{Awareness and Use of Text Structure}

Although all the letters have been replaced with x's you can probably tell what sort of text it is and even answer some questions about the contents: 


\title{
XXXXXX XX XXXXXXXXXX
}

XXXXXXX XXX XX XXX

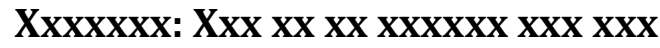

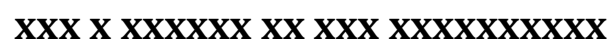

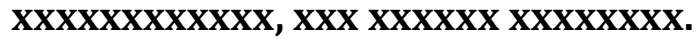

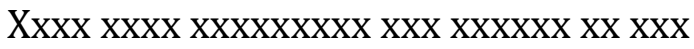

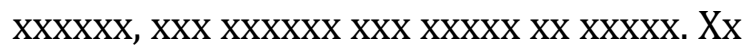

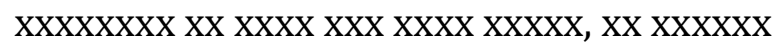

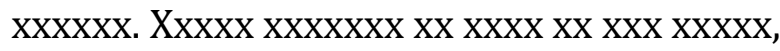

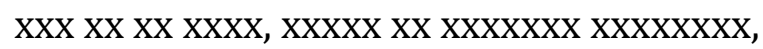

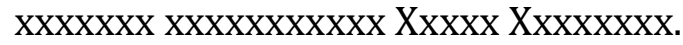

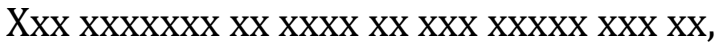

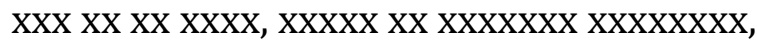

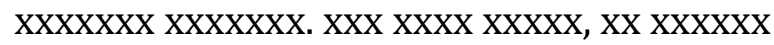

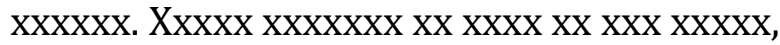
$\mathrm{XXX}$ XX XX XXXX $\mathrm{xx}$.
\end{abstract}

Xx XXXXXXXX XX XXXX XXX XXXX XXXXX, $\mathrm{xX}$

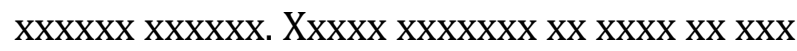

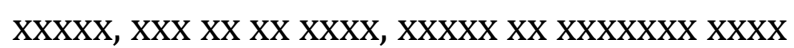
$\operatorname{xxxx} \mathrm{xxxxxxx}$.

Xx Xxxxxxxxx Xxxxxx

What sort of text do you think it is? (It may not look exactly the same in an American format as it does in this European format). Where do you think you could find a brief summary of the contents? And where would you look for the author's name? Imagine that the news article - that is a likely genre - is about a managing director who stole $\$ 250$ million from her company. The article tells how the theft was discovered and what she was sentenced to. What could be the contents of the last paragraph?

Text genres are just conventional text structures used for specific purposes of communication. There are genres for personal updates (blog posts, postcards etc.) for fairy tales and other narratives, for information about nutritional facts (labels), for brief scientific reports (journal papers), meal choices (menus), and so on. Text genres are useful once they have been learned because the reader will quickly know what to expect from the text and where to read for certain types of information. 
Another way of looking at text structure is to look at the underlying logical structure - across genres (e.g., Meyer \& Freedle, 1984). One way to group the structures is the following:

Description: A topic is described by listing various characteristics, features, and also examples.

Sequence: Items are presented in an order, typically chronological.

Compare and contrast: Two or more items are presented and how they are similar and also different is discussed.

Cause and effect: One or more causes and effects are detailed.

Problem and solution: A problem is stated and various solutions are then presented.

These underlying logical structures have typically been observed and taught in informational (expository) texts even though they also apply to narratives. The reader can benefit from identifying such underlying structures: The general idea of the text (or passage) becomes much simpler and thereby clearer, and the types of inferences needed are usually much easier to identify. Imagine, for example, that a text contrasts organic foods with traditionally produced foods. The text mentions some quality of organic foods, but says nothing about this quality or lack of it in traditional produce. Within the context of the comparecontrast structure, the reader would probably be right in inferring that the traditional produce does not have the same quality (to the same extent).

\section{How Does Awareness of Text Structure Develop?}

Before school entry, most children are familiar with at least one (major) text genre, that of stories (narratives). They have experiences with stories from cartoons and movies, picture books, spoken stories, and from books that they have listened to. However, there is also evidence that young children do not represent stories in quite the same hierarchically structured manner as older children and adults do. For example, young children are less likely than older children and adults to pay attention to characters' superordinate goals and to include them in their recalls of stories. The younger children may not pay as much attention to the character's main aim, for example, to retrieve a lost pet frog, as adults do. Instead of goals and internal states the younger children recall concrete events (Mandler \& Johnson, 1977; van den Broek, Lorch, \& Thurlow, 1996).

Some children are better than others at recalling the key events in stories. It is well documented that a child's ability to recall stories is predictive of how well the child will do in reading comprehension with stories later in school (Kendeou, 
van den Broek, White, \& Lynch, 2009; Oakhill \& Cain, 2012). Interestingly, this correlation over time is independent on the type of media in which the story was presented in early childhood. Hence, comprehension of the story in televised cartoons in 6 year olds is as predictive of later reading comprehension as early story comprehension is in other media, such as listening comprehension, at the age of 6 (Kendeou et al., 2009). This independence of the medium suggests that what matters is the child's ability to represent the story in a structured way. Obviously, relevant background knowledge is important for such representation.

\section{Difficulties with Text Structures}

Consider these stories about recent holidays told by three 6-year-olds from the same class:

Esther: We saw a whole lot of animals. I must not open the car window. I have a game with wild animals on my computer. My ice cream dripped on the seat. The end.

Luke: I helped my grandpa feed the geese. Then we had lunch. Afterwards it rained and we played cards. Then we went down to the sea. And then we had to go home.

Karen: We were in France to visit my aunt. We saw a big lion on the telly. It had escaped from a circus. It was dangerous. So we made lassos to catch the lion. We caught it right after it had gone dark. But it was the neighbour's cat.

The three stories are structured in very different ways. Esther's story is not a conventional story at all but more a description of a situation with an association to a computer game. Luke, on the other hand, tells a story with a series of events. His story could be an entry into a diary. The structure is the simplest possible, a string of events connected by and then, and then. Karen's story has a different structure, it has a setting, internal causality, and even a point. Clearly, the three 'stories' are structured at very different levels.

The quality of their story structures is linked with children's reading comprehension and reading difficulties (Cain, 2003; Shapiro \& Hudson, 1997). Cain (2003) found that 7- to 8-year-old children with reading comprehension difficulties were poorer at telling well-structured stories than their peers. They were even poorer than 6- to 7-year-old children who matched the older children on reading comprehension. The poor comprehenders were more likely to tell a non-story like Esther's especially when they were only given a title as a starting point.

The link between story structure awareness and reading comprehension is further supported by other findings. For example, poor comprehenders have 
been found to be less likely than their peers to produce continuations of stories that fit in with the structure of the stories (Englert \& Thomas, 1987). Even with informational text, poor structure awareness is linked to poorly structured understanding and recall even with well-structured texts (Taylor \& Samuels, 1983).

\section{How Can Awareness and Use of Text Structure Be Improved?}

There are at least three major paths to help readers gain awareness of text structures.

First, it is well documented that direct instruction in narrative structures, such as story grammar', is beneficial (e.g. Paris and Paris, 2007; Stetter \& Hughes, 2010, provide an overview). During such instruction, the readers will learn about the typical structure of stories. First, there is a setting (e.g. "once upon a time there was a ..."). But something is missing or the harmony is broken ("the terrible dragon abducted the little prince"). Several attempts are made to solve the problem ("Braveheart Victoria stepped in ..."), before a resolution is reached ("and they lived happily ever after"). When children know this structure it becomes easier for them to orient themselves in similar stories, to predict the events, and to produce well-organised summaries.

Second, it is possible to teach even children in the first grades logical structures of informational texts. For example, children can learn to spot key words that signal a compare-contrast structure: but, however, both, on the other hand. They can learn to apply generalizable questions, like "Which are the two things that were being compared in this paragraph?" "How are they alike?" How are they different?" Importantly, it has been found that children can work at this more general level and even learn as many details from the texts as when they are taught to focus on the informational details (Williams et al., 2007; 2009).

Third, readers can be taught graphic organisers and how to use them to represent the logical structure of texts. Such organisers comprise simple compare-contrast tables, Venn diagrams, flow charts, tree diagrams (for general concept and their more specific parts or examples). Such graphic organisers use the spatial orientation to represent logical relations (contrasts, causes and consequences, etc.) and thus they make the logical structure directly visible to the reader.

\section{Teaching the Components of Comprehension}

When a reader comprehends a text, the components of reading comprehension are weaved tightly together. This means that weaknesses in just one component 
can weaken comprehension significantly. It also means that the reader must know when to make use of each component. Consider the following short text:

The door suddenly opened and a young woman entered the office. The school psychologist looked up and said "do come in!" A little boy was trying to hide behind the woman. "Why didn't you do a vergence test?" asked the woman and continued, "we took Peter to the optometrist who discovered insufficient vergence".

The monitoring reader detects an inconsistency right at the beginning of this meeting: the school psychologist says "do come in" when the woman is already in the office. There is no immediate reason to issue this invitation.

One possible inference is that the psychologist offers the invitation as a polite way of reproaching the woman for not knocking on the door first. Perhaps the psychologist is annoyed with being disturbed and vents this in a mild way. Many other inferences are necessary to establish a coherent mental model of the situation: The woman is probably the boy's, Peter's, mother, and has probably been to see the school psychologist before about some problem of Peter's. Now she is annoyed with the psychologist because he or she has not diagnosed Peter properly earlier. She is probably also worried about Peter which may explain (but not excuse) her inconsiderate manners. Do her worries transfer to Peter? What does he think of his mother's behaviour?

The word vergence is likely to present a vocabulary challenge to the reader. Potentially the context provides a bit of a clue depending on the reader's knowledge of what optometrists do. The reader may infer that vergence is likely to have something to do with eyes and vision. The reader may also draw morphological analogies to convergence and divergence, again depending on his or her vocabulary knowledge.

The use of the definite form of nouns, "the door", "the office", "the school psychologist" indicates that the text should be read as fiction. The definite forms invite the reader to think of the office and the psychologist as well known entities, though they have not been introduced and described. Assuming that the text is a piece of fiction, the reader can set up a number of expectations about the structure of the text. There will be a protagonist, perhaps it is the psychologist because he or she is part of the scene that is presented as already given. The reader may expect that the conflict escalates, and if it does, the boy is likely to be a victim - very much depending on the knowledge and skills of the psychologist.

A teacher of reading comprehension must know such components of comprehension to assess them and to teach them (see Oakhill, Cain, \& Elbro, 2014, for a detailed account). However, there is no strong evidence that teaching single components of reading comprehension separately will lead to large and sustained gains in comprehension. There may be several reasons for this lack of 
transfer. One is that there are so many components that each of them only has modest influence on reading comprehension in general. Another is that children do not know when to use a particular component. For example, children may be good at understanding compare-contrast type texts when this structure is pointed out to them, but very poor at identifying texts with that structure (Williams et al., 2009).

A more productive way ahead is to teach the components of comprehension in an integrated fashion driven by reading for specific purposes. One simple reason is that fulfilling the purpose of reading is the only lasting motivation for reading. It is also the reading purpose that sets the criteria for the necessary quality (specification) of the reader's mental model of the text. The model is set up and specified by means of an integrated set of component processes.

In order to teach component processes in the complex context of text comprehension, the teacher needs to be able to identify the components that are needed. Important inferences make a lot of sense to students who need them to make sense of a text. Monitoring may turn an uninteresting text into a fascinating riddle. A search for context clues - and inference making - may give the hint that is needed to add new vocabulary knowledge and link a new bit of information to the reader's knowledge. The well-informed teacher will be able to seize such opportunities to help students become better comprehenders.

\section{References}

Anderson, R. C., Stevens, K. C., Shifrin, Z., \& Osborn, J. H. (1978). Instantiation of word meanings in children. Journal of Literacy Research, 10(2), 149-157.

Arnold, J. E., Brown-Schmidt, S., \& Trueswell, J. (2007). Children's use of gender and order-of-mention during pronoun comprehension. Language and Cognitive Processes, 22(4), 527-565.

Baddeley, A. D. (1986). Working memory. Oxford: Oxford University Press.

Baddeley, A. D. (1996). Your memory: A user's guide, 3rd edition. London: Prion Books.

Baddeley, A. D., \& Hitch, G. J. (1974). Working memory. In G. A. Bower (Ed.), Recent advances in learning and motivation (Vol. 8, pp. 47-90). New York: Academic Press.

Baker, L. (1984). Spontaneous versus instructed use of multiple standards for evaluating comprehension: Effects of age, reading proficiency, and type of standard. Journal of Experimental Child Psychology, 38(2), 289-311.

Barnes, M. A. \& Dennis, M. (1998). Discourse after early-onset hydrocephalus: Core deficits in children of average intelligence. Brain and Language, 61(3), 309-334. 
Barnes, M. A., Dennis, M., \& Haefele-Kalvaitis, J. (1996). The effects of knowledge availability and knowledge accessibility on coherence and elaborative inferencing in children from six to fifteen years of age. Journal of Experimental Child Psychology, 61(3), 216-241.

Barzillai, M., Morris, R., Lovett, M. \& Wolf, M. (2010), Poster presented at the annual meeting of the Society for Scientific Studies in Reading.

Bast, J., \& Reitsma, P. (1998). Analyzing the development of individual differences in terms of Matthew effects in reading: Results from a Dutch longitudinal study. Developmental Psychology, 34(6), 1373-1399.

Beck, I. L., \& McKeown, M. G. (2001). Inviting students into the pursuit of meaning. Educational Psychology Review, 13(3), 225-241.

Beck, I. L., McKeown, M.G., \& Kucan, L. (2005). Choosing words to teach. In A. Hiebert \& M. Kamil (Eds.), Teaching and learning vocabulary: Bringing research to practice (pp. 209-222). Mahwah, NJ: Erlbaum.

Beck, I., Perfetti, C., \& McKeown, M. (1982). Effects of long-term vocabulary instruction on lexical access and reading comprehension. Journal of Educational Psychology, 74, 506-521.

Best, R. M., Floyd, R. G., \& McNamara, D. S. (2008). Differential competencies contributing to children's comprehension of narrative and expository texts. Reading Psychology, 29(2), 137-164.

Biemiller, A. (2005). Size and sequence in vocabulary development: Implications for choosing words for primary grade vocabulary instruction. In A. Hiebert \& M. Kamil (Eds.), Teaching and learning vocabulary: Bringing research to practice (pp. 223-242). Mahwah, NJ: Erlbaum.

Biemiller, A., \& Boote, C. (2006). An effective method for building meaning vocabulary in primary grades. Journal of Educational Psychology, 98(1), 4462.

Bishop, D. V. M. (1997). Uncommon understanding: Development and disorders of language comprehension in children. Hove: Psychology Press.

Bishop, D. V. M., (2001). Uncommon Understanding. East Sussex, England: Psychology Press.

Blewitt, P., Rump, K. M., Shealy, S. E., \& Cook, S. A. (2009). Shared book reading: When and how questions affect young children's word learning. Journal of Educational Psychology, 101(2), 294-304.

Bloom, L., Lahey, M., Hood, L., Lifter, K., \& Fiess, K. (1980). Complex sentences: Acquisition of syntactic connectives and the semantic relations they encode. Journal of Child Language, 7(2), 235-261.

Bormuth, J. R. (1967). Cloze readability procedure. CSEIP Occasional Report 1. Los Angeles, CA: University of California.

Bowers, P. N., \& Kirby, J. R. (2010). Effects of morphological instruction on vocabulary acquisition. Reading and Writing, 23(5), 515-537. 
Bowers, P. N., Kirby, J. R., \& Deacon, S. H. (2010). The effects of morphological instruction on literacy skills A systematic review of the literature. Review of Educational Research, 80(2), 144-179.

Brady, S. A. (2011). Efficacy of phonics teaching for reading outcomes: Indications from post NRP research. In S. A. Brady \& D. Braze \& C. A. Fowler (Eds.), Explaining Individual Differences in Reading. Theory and Evidence (pp. 69-96). New York: Psychology Press.

Bransford, J. D., \& Johnson, M. K. (1972). Contextual prerequisites for understanding: Some investigations of comprehension and recall. Journal of Verbal Learning and Verbal Behavior, 11(6), 717-726.

Cain, K. (1996). Story knowledge and comprehension skill. In C. Cornoldi \& J. Oakhill (Eds.), Reading comprehension difficulties: processes and remediation (pp. 167-192). Mahwah, NJ: LEA.

Cain, K. (1999). Ways of reading: How knowledge and use of strategies are related to reading comprehension. British Journal of Developmental Psychology, 17(2), 293-309.

Cain, K. (2003). Text comprehension and its relation to coherence and cohesion in children's fictional narratives. British Journal of Developmental Psychology, 21(3), 335-351.

Cain, K. (2007). Syntactic awareness and reading ability: Is there any evidence for a special relationship? Applied Psycholinguistics, 28(4), 679-694.

Cain, K., \& Nash, H. M. (2011). The influence of connectives on young readers' processing and comprehension of text. Journal of Educational Psychology, 103(2), 429-441.

Cain, K., \& Oakhill, J. V. (1999). Inference making and its relation to comprehension failure. Reading and Writing. An Interdisciplinary Journal, 11(5-6), 489-503.

Cain, K., \& Oakhill, J. V. (2006). Profiles of children with specific reading comprehension difficulties. British Journal of Educational Psychology, 76(4), 683-696.

Cain, K., \& Oakhill, J. V. (2011). Matthew effects in young readers reading comprehension and reading experience aid vocabulary development. Journal of Learning Disabilities, 44(5), 431-443.

Cain, K. \& Oakhill, J. V. (in press). Reading comprehension and vocabulary: Is vocabulary more important for some aspects of comprehension? L'Année Psychologique/ Topics in Cognitive Psychology.

Cain, K., Oakhill, J. V., Barnes, M. A., \& Bryant, P. E. (2001). Comprehension skill, inference making ability and their relation to knowledge. Memory and Cognition, 29(6), 850-859. 
Cain, K., Oakhill, J. V., \& Bryant, P. E. (2004). Children's reading comprehension ability: Concurrent prediction by working memory, verbal ability, and component skills. Journal of Educational Psychology, 96(1), 671-681.

Cain, K., Oakhill, J. V., \& Lemmon, K. (2004). Individual differences in the inference of word meanings from context: the influence of reading comprehension, vocabulary knowledge, and memory capacity. Journal of Educational Psychology, 96(4), 671-681.

Cain, K., Oakhill, J. V., \& Lemmon, K. (2005). The relation between children's reading comprehension level and their comprehension of idioms. Journal of Experimental Child Psychology, 90(1), 65-87.

Cain, K., Patson, N., \& Andrews, L. (2005). Age-and ability-related differences in young readers' use of conjunctions. Journal of Child Language, 32(4), 877892.

Cain, K., \& Towse, A. S. (2008). To get hold of the wrong end of the stick: Reasons for poor idiom understanding in children with reading comprehension difficulties. Journal of Speech, Language, and Hearing Research, 51(6), 15381549.

Cain, K., Towse, A. S., \& Knight, R. S. (2009). The development of idiom comprehension: An investigation of semantic and contextual processing skills. Journal of Experimental Child Psychology, 102(3), 280-298.

Carney, J. J., Anderson, D., Blackburn, C., \& Blessing, D. (1984). Preteaching vocabulary and the comprehension of social studies materials by elementary school children. Social Education, 48(3), 195-196.

Carroll, J. B. (1993). Human Cognitive Abilities: A Survey of Factor-Analytic Studies. New York: Cambridge University Press.

Catts, H. W., Compton, D., Tomblin, J. B., \& Bridges, M. S. (2012). Prevalence and nature of late-emerging poor readers. Journal of Educational Research, 104(1), 166-181.

Catts, H. W., Hogan, T. P., \& Adlof, S. M. (2005). Developmental changes in reading and reading disabilities. In H. W. Catts \& A. G. Kamhi (Eds.), The connections between language and reading disabilities (pp. 25-40). Mahwah, NJ: Lawrence Erlbaum.

Chall, J. S., Jacobs, V. A., \& Baldwin, L. E. (1990). The Reading Crisis: Why Poor Children Fall Behind. Cambridge, Mass: Harvard University Press

Chapman, L. J. (1983). Reading development and cohesion. Exeter: Heinemann.

Charniak, E. (1972). Toward a model of children's story comprehension. (Technical Report 266). Cambridge, MA: Artificial Intelligence Laboratory, MIT.

Chien, Y. C., \& Wexler, K. (1990). Children's knowledge of locality conditions in binding as evidence for the modularity of syntax and pragmatics. Language Acquisition, 1(3), 225-295. 
Chomsky, C. (1969). The Acquisition of Syntax in Children from 5-10. Cambridge, Mass.: M.I.T. Press

Connolly, J. (1999). Every Dead Thing. New York: Simon \& Schuster.

Coyne, M. D., McCoach, D. B., \& Kapp, S. (2007). Vocabulary intervention for kindergarten students: Comparing extended instruction to embedded instruction and incidental exposure. Learning Disability Quarterly, 30(2), 7488.

Crosson, A. C., Lesaux, N. K., \& Martiniello, M. (2008). Factors that influence comprehension of connectives among language minority children from Spanish-speaking backgrounds. Applied Psycholinguistics, 29(4), 603-625.

Cunningham, A. E. (2005). Vocabulary growth through independent reading and reading aloud to children. In E. H. Hiebert \& M. L. Kamhi (Eds.), Teaching and learning vocabulary: Bringing research to practice (pp. 45-68). Mahwah, NJ: LEA.

Cutting, L. E., \& Scarborough, H. S. (2006). Prediction of reading comprehension: Relative contributions of word recognition, language proficiency, and other cognitive skills can depend on how comprehension is measured. Scientific Studies of Reading, 10(3), 277-299.

Daneman, M., \& Carpenter, P. A. (1980). Individual differences in working memory and reading. Journal of Verbal Learning and Verbal Behavior, 19(4), 450-466.

Davis, F. B. (1944). Fundamental factors of comprehension in reading. Psychometrika, 9(3), 185-197.

Davis, F. B. (1968). Research in comprehension in reading. Reading Research Quarterly, 3(4), 499-545.

de Sousa, I., \& Oakhill, J. V. (1996). Do levels of interest have an effect on children's comprehension monitoring performance? British Journal of Educational Psychology, 66(4), 471-482.

de Jong, P. F., \& van der Leij, A. (2002). Effects of phonological abilities and linguistic comprehension on the development of reading. Scientific Studies of Reading, 6(1), 51-77.

Duke, N. K. (2000). 3.6 minutes per day: The scarcity of informational texts in first grade. Reading Research Quarterly, 35(2), 202-224.

Dunn, L. M., Dunn, L. M., Whetton, C., \& Pintilie, D. (1982). British Picture Vocabulary Scale. London: NFER-Nelson.

Ehrlich, M. F., Rémond, M., \& Tardieu, H. (1999). Processing of anaphoric devices in young skilled and less skilled comprehenders: Differences in metacognitive monitoring. Reading and Writing, 11(1), 29-63.

Elbro, C., \& Arnbak, E. (2002). Components of reading comprehension as predictors of educational achievement. In E. Hjelmquist \& C. von Euler (Eds.), Dyslexia and literacy (pp. 69-83). London: Whurr. 
Elbro, C., \& Buch-Iversen, I. (2013). Activation of background knowledge for inference making: Effects on reading comprehension. Scientific Studies of Reading, 17(6), 435-452.

Elbro, C., \& Knudsen, L. (2010). The importance of genre knowledge for text comprehension. Insights from a training study. Paper presented at the Annual meeting of the Society for Text and Discourse, August 16-18. Chicago, USA.

Englert, C. S., \& Hiebert, E. F. (1984). Children's developing awareness of text structures in expository materials. Journal of Educational Psychology, 76(1), 65-74.

Englert, C. S., \& Thomas, C. C. (1987). Sensitivity to text structure in reading and writing: A comparison between learning-disabled and non-learning disabled students. Learning Disability Quarterly, 10(2), 93-105.

Florit, E., Roch, M., \& Levorato, M. C. (2011). Listening text comprehension of explicit and implicit information in preschoolers: The role of verbal and inferential skills. Discourse Processes, 48(2), 119-138.

Gallini, J., Spires, H., Terry, S., \& Gleaton, J. (1993). The influence of macro and micro-level cognitive strategies training on text learning. Journal of Research and Development in Education, 26(3), 164-178.

Gambrell, L. B., \& Bales, R. J. (1986). Mental imagery and the comprehensionmonitoring performance of fourth- and fifth-grade poor readers. Reading Research Quarterly, 21(4), 454-464.

Gellert, A. S., \& Elbro, C. (2013). Cloze tests may be quick, but are they dirty? Development and preliminary validation of a Cloze test of reading comprehension. Journal of Psychoeducational Assessment, 31(1), 16-28.

Gernsbacher, M. A., \& Hargreaves, D. J. (1988). Accessing sentence participants: The advantage of first mention. Journal of Memory and Language, 27(6), 699717.

Gernsbacher, M. M., Varner, K. R., \& Faust, M. E. (1990). Investigating individual differences in general comprehension skill. Journal of Experimental Psychology: Learning, Memory and Cognition, 16(3), 430-445.

Geva, E., \& Ryan, E. B. (1985). Use of conjunctions in expository texts by skilled and less skilled readers. Journal of Reading Behavior, 17(4), 331-346.

Gough, P. B., \& Hillinger, M. L. (1980). Learning to read: An unnatural act. Bulletin of the Orton Society, 30(1), 179-196.

Gough, P. B., Hoover, W. A., \& Peterson, C. L. (1996). Some observations on a simple view of reading. In C. Cornoldi \& J. Oakhill (Eds.), Reading comprehension difficulties. Processes and intervention (pp. 1-13). Mahwah, NJ: Erlbaum.

Gough, P. B., \& Tunmer, W. E. (1986). Decoding, reading, and reading disability. Remedial and Special Education, 7(1), 6-10. 
Hall, K. M., Markham, J. C., \& Culatta, B. (2005). The development of the Early Expository Comprehension Assessment (EECA): A look at reliability. Communication Disorders Quarterly, 26(4), 195-206.

Halliday, M. A. K., \& Hasan, R. (1976). Cohesion in English. London: Longman. Irwin, J. W., \& Pulver, C. J. (1984). Effects of explicitness, clause order, and reversibility on children's comprehension of causal relationships. Journal of Educational Psychology, 76, 399-407.

Johnson-Laird, P. N. (1983). Mental models: Towards a cognitive science of language, inference, and consciousness. Cambridge, MA: Harvard University Press.

Kail, M. l. (1976). Strategies of comprehension of personal pronouns among young children. Enfance, 4-5, 447-466.

Kail, M., \& Weissenborn, J. (1991). Connectives: Developmental issues. In G. Piéraut-le-Bonniec \& M. Dolitsky (Eds.), Language bases... Discourse bases: Some aspects of contemporary French-language psycholinguistics research (pp. 125-142). Amsterdam: Benjamins.

Keenan, J. M., \& Betjemann, R. S. (2006). Comprehending the Gray Oral Reading Test without reading it: Why comprehension tests should not include passage-independent items. Scientific Studies of Reading, 10(4), 368-380.

Keenan, J. M., Betjemann, R. S., \& Olson, R. K. (2008). Reading comprehension tests vary in the skills they assess: Differential dependence on decoding and oral comprehension. Scientific Studies of Reading, 12(3), 281-300.

Kendeou, P., Bohn-Gettler, C., White, M. J., \& Van Den Broek, P. (2008). Children's inference generation across different media. Journal of Research in Reading, 31(3), 259-272.

Kendeou, P., van den Broek, P., White, M., \& Lynch, J. S. (2009). Predicting reading comprehension in early elementary school: The independent contributions of oral language and decoding skills. Journal of Educational Psychology, 101(4), 765-778.

Kintsch, W. (1998). Comprehension: A paradigm for cognition. New York: Cambridge university press.

Leach, J. M., Scarborough, H. S., \& Rescorla, L. (2003). Late-emerging reading disabilities. Journal of Educational Psychology, 95(2), 211-224.

Lepola, J., Lynch, J., Laakkonen, E., Silvén, M., \& Niemi, P. (2012). The role of inference making and other language skills in the development of narrative listening comprehension in 4-6-year-old children. Reading Research Quarterly, 47(3), 259-282.

Levorato, M. C., Nesi, B., \& Cacciari, C. (2004). Reading comprehension and understanding idiomatic expressions: A developmental study. Brain and Language, 91(3), 303-314. 
Levorato, M. C., Roch, M., \& Nesi, B. (2007). A longitudinal study of idiom and text comprehension. Journal of Child Language, 34(3), 473-494.

Lynch, J. S., \& van den Broek, P. (2007). Understanding the glue of narrative structure: Children's on- and off-line inferences about characters' goals. Cognitive Development, 22(3), 323-340.

Lynch, J. S., van den Broek, P., Kremer, K., Kendeou, P., White, M. J., \& Lorch, E. P. (2008). The development of narrative comprehension and its relation to other early reading skills. Reading Psychology, 29(4), 327-365.

Mandler, J. M., \& Johnson, N. S. (1977). Remembrance of things parsed: Story structure and recall. Cognitive Psychology, 9(1), 111-151.

Markman, E. M. (1979). Realizing that you don't understand: Elementary school children's awareness of inconsistencies. Child Development, 50, 643-655.

Mayer, M. (1969). Frog, where are you? New York: Penguin Putnam Inc.

McMaster, K. L., van den Broek, P., Espin, C. A., White, M. J., Rapp, D. N., Kendeou, P., Bohn Gettler, C. M., \& Carlson, S. (2012). Making the right connections: Differential effects of reading intervention for subgroups of comprehenders. Learning and Individual Differences, 22(1), 100-111.

McNamara, D. S., \& Kintsch, W. (1996). Learning from texts: Effects of prior knowledge and text coherence. Discourse Processes, 22, 247-288.

Medo, M. A., \& Ryder, R. J. (1993). The effects of vocabulary instruction on readers' ability to make causal connections. Literacy Research and Instruction, 33(2), 119-134.

Megherbi, H., \& Ehrlich, M. F. (2005). Language impairment in less skilled comprehenders: The on-line processing of anaphoric pronouns in a listening situation. Reading and Writing, 18(7-9), 715-753.

Mehegan, C. \& Dreifuss, F. E. (1972). Hyperlexia. Neurology, 22(11), 1105-1111.

Meyer, B. J., \& Freedle, R. O. (1984). Effects of discourse type on recall. American Educational Research Journal, 21(1), 121-143.

Muter, V., Hulme, C., Snowling, M. J., \& Stevenson, J. (2004). Phonemes, rimes, vocabulary, and grammatical skills as foundations of early reading development: Evidence from a longitudinal study. Developmental Psychology, 40(5), 665-681.

Nagy, W. E., \& Anderson, R. C. (1984). How many words are there in printed school English? Reading Research Quarterly, 19(3), 304-330.

Nagy, W. E., \& Herman, P. A. (1987). Breadth and depth of vocabulary knowledge: Implications for acquisition and instruction. In M. G. McKeown \& M. E. Curtis (Eds.), The nature of vocabulary acquisition (pp. 19-36). Hillsdale, NJ: Erlbaum.

Nagy, W. E., \& Scott, J. (2000). Vocabulary processes. In M. Kamil, P. Mosenthal, P. D. Pearson \& R. Barr (Eds.), Handbook of reading research. Vol. III (pp. 269284). Mahwah, NJ: Erlbaum. 
Nation, K. (1999). Reading skills in hyperlexia: A developmental perspective. Psychological Bulletin, 125(3), 338-355.

Nation, K., Cocksey, J., Taylor, J. S., \& Bishop, D. V. (2010). A longitudinal investigation of early reading and language skills in children with poor reading comprehension. Journal of Child Psychology and Psychiatry, 51(9), 1031-1039.

Nation, K., \& Norbury, C. F. (2005). Why reading comprehension fails: Insights from developmental disorders. Topics in Language Disorders, 25(1), 21-32.

Nation, K., \& Snowling, M. J. (1998). Semantic processing and the development of word-recognition skills: Evidence from children with reading comprehension difficulties. Journal of Memory and Language, 39(1), 85-101.

National Reading Panel. (2000). Teaching children to read: An evidence-based assessment of the scientific research literature on reading and its implications for reading instruction. Washington, DC: The National Institute of Child Health and Human Development (http://www.nichd.nih. gov/publications/nrp/smallbook.htm).

Neale, M. D. (1997). The Neale analysis of reading ability-Revised (NARA-II). Windsor, England: NFER-Nelson.

Oakhill, J. V. (1982). Constructive processes in skilled and less-skilled comprehenders' memory for sentences. British Journal of Psychology, 73(1), 13-20.

Oakhill, J. V., \& Cain, K. (2012). The precursors of reading ability in young readers: Evidence from a four-year longitudinal study. Scientific Studies of Reading, 16(2), 91-121.

Oakhill, J. V. \& Cain, K. (2017). Children with Specific Text Comprehension Problems. In Cain, K., Compton, D. \& Parrila, R. (Eds.) Theories of Reading Development. Amsterdam, The Netherlands: John Benjamins.

Oakhill, J. V., Cain, K., \& Bryant, P. E. (2003). The dissociation of word reading and text comprehension: Evidence from component skills. Language and Cognitive Processes, 18(4), 443-468.

Oakhill, J. V., Cain, K., \& McCarthy, D. (2015). Inference Processing in Children: the contributions of depth and breadth of vocabulary knowledge. In O'Brien, E., Cook, A. \& Lorch, R. (Eds.), Inferences During Reading, Cambridge University Press.

Oakhill, J. V., Cain, K., McCarthy, D., \& Field, Z. (2012). Making the link between vocabulary knowledge and comprehension skill. In Britt, A., Goldman, S., \& Rouet, J-F. (Eds.), From words to reading for understanding (pp. 101). Hoboken, NJ: Routledge.

Oakhill, J. V., \& Yuill, N. (1986). Pronoun resolution in skilled and less-skilled comprehenders: Effects of memory load and inferential complexity. Language and Speech, 29(1), 25-37. 
Oakhill, J. V., Yuill, N., \& Donaldson, M. L. (1990). Understanding of causal expressions in skilled and less skilled text comprehenders. British Journal of Developmental Psychology, 8(4), 401-410.

Oakhill, J.V., Hartt, J., \& Samols, D. (2005). Levels of comprehension monitoring and working memory in good and poor comprehenders. Reading and Writing, 18, 657-686

Ouellette, G. P. (2006). What's meaning got to do with it: The role of vocabulary in word reading and reading comprehension. Journal of Educational Psychology, 98(3), 554-566.

Palinscar, A. S., \& Brown, A. L. (1984). Reciprocal teaching of comprehensionfostering and comprehension-monitoring activities. Cognition and Instruction, 1(2), 117-175.

Pappas, C. C. (1993). Is narrative 'primary'? Some insights from kindergarteners' pretend readings of stories and information books. Journal of Reading Behavior, 25(1), 97-129.

Paris, S. G. (2005). Reinterpreting the development of reading skills. Reading Research Quarterly, 40(2), 184-202.

Paris, A. H., \& Paris, S. G. (2003). Assessing narrative comprehension in young children. Reading Research Quarterly, 38(1), 36-76.

Paris, A. H., \& Paris, S. G. (2007). Teaching narrative comprehension strategies to first graders. Cognition and Instruction, 25(1), 1-44.

Paris, S. G., \& Jacobs, J. E. (1984). The benefits of informed instruction for children's reading awareness and comprehension skills. Child Development, 55(6), 2083-2093.

Perfetti, C. A. (1985). Reading ability. New York, NY: Oxford University Press.

Peterson, C. (1986). Semantic and pragmatic uses of 'but'. Journal of Child Language, 13(3), 583-590.

Peterson, C., \& McCabe, A. (1987). The connective 'and': Do older children use it less as they learn other connectives. Journal of Child Language, 14(2), 375381.

Pichert, J. W. \& Anderson, R. C., (1977). Taking different perspectives on a story. Journal of Educational Psychology, 69, 309-315

Pike, M. M., Barnes, M. A., \& Barron, R. W. (2010). The role of illustrations in children's inferential comprehension. Journal of Experimental Child Psychology, 105(3), 243-255.

Pinker, S. (1994). The language instinct. The new science of language and mind. London: Allen Lane.

Pressley, G. M. (1976). Mental imagery helps eight-year-olds remember what they read. Journal of Educational Psychology, 68(3), 355-359.

Pressley, M., \& Afflerbach, P. P. (1995). Verbal protocols of reading: The nature of constructively responsive reading. Hillsdale, NJ: Erlbaum. 
Protopapas, A., Sideridis, G. D., Mouzaki, A., \& Simos, P. G. (2007). Development of lexical mediation in the relation between reading comprehension and word reading skills in Greek. Scientific Studies of Reading, 11(3), 165-197.

Pyykkonen, P., \& Jarvikivi, J. (2012). Children and situation models of multiple events. Developmental Psychology, 48, 521-529.

Reid, J. (1972). Children's comprehension of syntactic features found in some extension readers. Occasional paper, Centre for Research in Educational Sciences, University of Edinburgh.

Rosenshine, B., Meister, C., \& Chapman, S. (1996). Teaching Students to Generate Questions: A Review of the Intervention Studies. Review of Educational Research, 66(2), 181-221.

Sachs, J. S. (1967). Recognition memory for syntactic and semantic aspects of connected discourse. Perception \& Psychophysics, 2(9), 437-442.

Scarborough, H. (2001). Connecting early language and literacy to later reading (dis)abilities: Evidence, theory, and practice. In S. B. Neuman \& D. K. Dickinson (Eds.), Handbook of Early Literacy (pp. 97-110). New York: Guilford Press.

Seigneuric, A., \& Ehrlich, M. F. (2005). Contribution of working memory capacity to children's reading comprehension: A longitudinal investigation. Reading and Writing, 18(7-9), 617-656.

Seymour, P. H. K., \& Elder, L. (1986). Beginning reading without phonology. Cognitive Neuropsychology, 3(1), 1-36.

Shanahan, T., Kamil, M. L., \& Tobin, A. W. (1982). Cloze as a measure of intersentential comprehension. Reading Research Quarterly, 17(2), 229-255.

Shapiro, B. K., \& Hudson, J. A. (1997). Coherence and cohesion in children's stories. In J. Costermans \& M. Fayol (Eds.), Processing interclausal relationships: studies in the production and comprehension of text (pp. 23-48). Mahwah, NJ: Lawrence Erlbaum Associates.

Share, D. L. (1995). Phonological recoding and self-teaching: sine qua non of reading acquisition. Cognition, 55(2), 151-218.

Skarakis-Doyle, E. (2002). Young children's detection of violations in familiar stories and emerging comprehension monitoring. Discourse Processes, 33(2), 175-197.

Smith, E. E., \& Swinney, D. A. (1992). The role of schemas in reading text: A realtime examination. Discourse Processes, 15(3), 303-316.

Snowling, M., \& Frith, U. (1986). Comprehension in "hyperlexic" readers. Journal of Experimental Child Psychology, 42(3), 392-415.

Snowling, M. J., \& Hulme, C. (2005). Learning to read with a language impairment. In M. J. Snowling \& C. Hulme (Eds.), The Science of Reading: A Handbook (pp. 397-412). Oxford: Blackwell. 
Song, H. J., \& Fisher, C. (2005). Who's "she"? Discourse prominence influences preschoolers' comprehension of pronouns. Journal of Memory and Language, 52(1), 29-57.

Sparks, E., \& Deacon, S. H. (2013). Morphological awareness and vocabulary acquisition: A longitudinal examination of their relationship in Englishspeaking children. Applied Psycholinguistics, 1-23.

Spooren, W., \& Sanders, T. (2008). The acquisition order of coherence relations: On cognitive complexity in discourse. Journal of Pragmatics, 40(12), 20032026.

Spörer, N., Brunstein, J. C., \& Kieschke, U. (2009). Improving students' reading comprehension skills: Effects of strategy instruction and reciprocal teaching. Learning and Instruction, 19(3), 272-286.

Stahl, S. A., \& Fairbanks, M. M. (1986). The effects of vocabulary instruction: A model-based meta-analysis. Review of Educational Research, 56(1), 72-110.

Stanovich, K. E. (1986). Matthew effects in reading: Some consequences of individual differences in the acquisition of literacy. Reading Research Quarterly, 21(4), 360-407.

Stein, N. L., \& Glenn, C. G. (1982). Children's concept of time: The development of story schema. In W. Friedman, J. (Ed.), The developmental psychology of time (pp. 255-282). New York: Academic Press.

Taylor, B. M., \& Samuels, S. J. (1983). Children's use of text structure in the recall of expository material. American Educational Research Journal, 20(4), 517528.

Tannenbaum, K. R., Torgesen, J. K., \& Wagner, R. K. (2006). Relationships between word knowledge and reading comprehension in third-grade children. Scientific Studies of Reading, 10(4), 381-398.

Thorndike, R. L. (1973). Reading as reasoning. Reading Research Quarterly, 9(2), 135-147.

Tomesen, M., \& Aarnoutse, C. (1998). Effects of an Instructional Programme for Deriving Word Meanings 1. Educational Studies, 24(1), 107-128.

Tompkins, V., Guo, Y., \& Justice, L., M. (2013). Inference generation, story comprehension, and language skills in the preschool years. Reading \& Writing, 26(3), 403-429.

Tong, X., Deacon, S. H., Kirby, J. R., Cain, K., \& Parrila, R. (2011). Morphological awareness: A key to understanding poor reading comprehension in English. Journal of Educational Psychology, 103(3), 523-534.

Tunmer, W. E., Nesdale, A. R., \& Pratt, C. (1983). The development of young children's awareness of logical inconsistencies. Journal of Experimental Child Psychology, 36(1), 97-108.

Tyler, L. K. (1983). The development of discourse mapping processes: The online interpretation of anaphoric expressions. Cognition, 13(3), 309-341. 
van den Broek, P. W. (1997). Discovering the cement of the universe: The development of event comprehension from childhood to adulthood. In P. W. van den Broek, P. J. Bauer \& T. Bourg (Eds.), Developmental Spans in Event Comprehension and Representation (pp. 321-342). Mahwah, NJ: Lawrence Erlbaum Associates.

van den Broek, P. W., Lorch, R. F., Linderholm, T., \& Gustafson, M. (2001). The effects of readers' goals on inference generation and memory for text. Memory and Cognition, 29(8), 1081-1087.

van den Broek, J., Lorch, E. P., \& Thurlow, R. (1996). Children's and adults memory for television stories: The role of causal factors, story-grammar categories, and hierarchical structure. Child Development, 67(6), 3010-3028.

Venezky, R. (2000). The origins of the present-day chasms between adult literacy needs and school literacy instruction. Scientific Studies of Reading, 4(1), 1939.

Walberg, H. J., Strykowski, B. F., Rovai, E., \& Hung, S. S. (1984). Exceptional performance. Review of Educational Research, 54(1), 87-112.

Weekes, B. S., Hamilton, S., Oakhill, J. V., \& Holliday, R. E. (2008). False recollection in children with reading comprehension difficulties. Cognition, 106(1), 222-233.

Whaley, J. F. (1981). Readers' expectations for story structure. Reading Resarch Quarterly, 17(1), 90-114.

Williams, J. P., Nubla-Kung, A. M., Pollini, S., Stafford, K. B., Garcia, A., \& Snyder, A. E. (2007). Teaching cause-effect text structure through social studies content to at-risk second graders. Journal of Learning Disabilities, 40(2), 111-120.

Williams, J. P., Stafford, K. B., Lauer, K. D., Hall, K. M., \& Pollini, S. (2009). Embedding reading comprehension training in content-area instruction. Journal of Educational Psychology, 101(1), 1-20.

Yuill, N. M., \& Oakhill, J. V. (1988). Effects of inference awareness training on poor reading comprehension. Applied Cognitive Psychology, 2(1), 33-45.

Yuill, N. M., \& Oakhill, J. V. (1991). Children's problems in text comprehension: An experimental investigation. Cambridge: Cambridge University Press.

Yuill, N. M., Oakhill, J. V., \& Parkin, A. (1989). Working memory, comprehension ability and the resolution of text anomaly. British Journal of Psychology, 80(3), 351-361.

Zwaan, R. A. (1994). Effect of Genre Expectations on Text Comprehension. Journal of Experimental Psychology: Learning, Memory, and Cognition, 20(4), 920-933. 